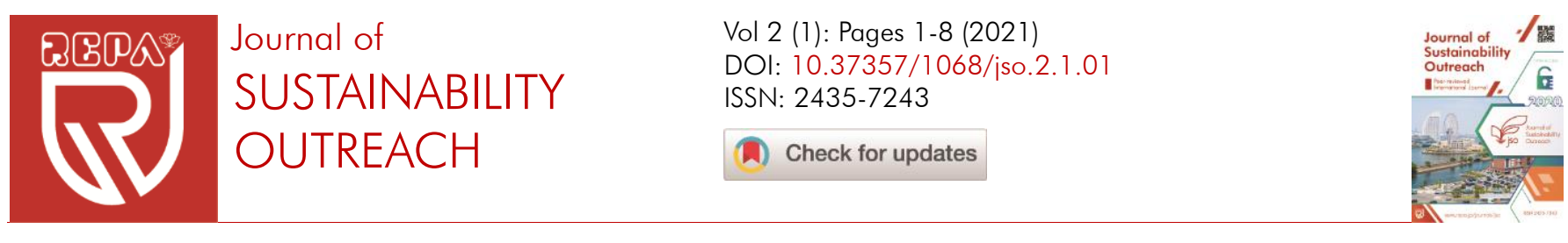

\title{
A review on energy efficiency for pathetic environmental trends mitigation
}

Mir Sayed Shah Danish 1,4*, Tomonobu Senjyu ${ }^{2 *}$, Mikaeel Ahmadi², Gul Ahmad Ludin², Mohammad Hamid Ahadi ${ }^{3}$, Hedayatullah Karimy ${ }^{4}$ and Mahdi Khosravy ${ }^{5}$

${ }_{1}^{1}$ Strategic Research Project Center, University of the Ryukyus, 1 Senbaru 9030213, Japan

2Department of Electrical and Electronics Engineering, Faculty of Engineering, University of the Ryukyus, Okinawa 903-0213, Japan

${ }^{3}$ Department of Intellectual Cooperation, Research and Education Promotion Association (REPA), Okinawa 900-0015, Japan

${ }^{4}$ Department of Energy Engineering, Faculty of Engineering, Kabul University, Kabul 1006, Afghanistan

${ }_{5}^{5}$ Media Integrated Communication Laboratory, Graduate School of Engineering, Osaka University, 1-1 Yamadaoka, Suita, Osaka 565-0871, Japan

Articl Open Access Published

Keywords

- Energy efficiency

- Exergy

- Climate change

- Pathetic environmental trends

- Environmental sustainability

\section{ABSTRACT}

Environmental sustainability and climate changes mitigation are linked with energy efficiency and renewable energy deployment. Whereas, renewable energy exploitation at large scale generation needs high initial investment, which is not achievable in short to medium terms, especially in developing countries. Therefore, energy efficiency measures as a good alternative for environmental sustainability are the researchers' interest to evaluate its potential from individual energy consumers to utilityscale (generation, transmission, and distribution). Referring to literature and the connection between the second law of thermodynamics and environmental impact, environmental effects are reduced due to low energy when energy efficiency increases. Therefore, assuring demanding efficiency, interrelations studies, and impact analysis of influential factors are known exigence. This study draws a thematic perspective that involves an exhaustive investigation, explaining the relationship between exergy, environment, and energy within optimum efficiency requirements. Also, this study deals with indicators and indices in adapt to energy and environmental demand to reveal the underlying fundamental impressing forces regarding efficiency improvement.

Received: July 20, 2021; Revised: August 10, 2021; Accepted: August 11, 2021; Published: August 20, 2021 (c) 2021 REPA. All rights reserved.

\section{Introduction}

Making environmental-friendly habit starts with the individual, which does not cost, but saving natural assets for future generations, calling environmental sustainability, which relies on essential energy conservation (switch of light) to advanced energy conservation (improving efficiencies measures). Therefore, energy conservation and efficiency impact environmental sustainability and climate change mitigation required an exhaustive study covering individual energy consumers to energy utilities and plant generation, transmission, and distribution efficiencies. In a constrained-greenhouse gases emissions world, energy conservation through energy efficiency, controlling environmental distress, and economic overruns at household to utility scales [1]. All told, energy efficiency goals require an emerging framework to integrate socioeconomic benefits in a broader range of stakeholders with various engagement and influential levels. Economic indicators are needed to assess the economic impact of renewable energy sources, including costs and return analysis and payback period. The costs of renewable energy systems are capital costs, replacement costs, operation, and maintenance costs [2].

\section{Energy sustainability}

After the industrial revolution, energy has been relatively cheap and plenty for a long time, and there has been little concern about climate change and sustainability [3]. At present, this is not a viable scenario anymore to utilize nonrenewable energy resources and pursue to rely on renewable energy deployment and energy efficiency as the alternative for increasing demand for energy. Deployment of renewable energy sources like solar, wind, geothermal, biomass, hydrogen, and hydraulic is increasing in recent years. This is because of their advantages to the environmental impacts like less pollution, less emission, and less fossil fuel resources usage. Therefore, environmental, economic, institutional, social, and technical aspects are the main general dimensions for environmental-friendly energy system planning and design.

Energy is primarily extracted, transported, and utilized in conversion in electricity and heat production, which are the two main energy uses. Technology has grown the energy sector with renewable energy and storage technologies gaining large shares and proposals for new storage systems to increase flexibility and stability of the systems to mitigate the possible risk of blackouts. However, power systems are associated with possible blackouts, which can be occurred even in any system, e.g., Tokyo blackout on 23 July 1987; Amalgamated Kingdom, Sweden, Canada, Denmark, Italy, and the Cumulated States blackouts in 2003 [4]. Economic and competitive electricity markets push the utilities to operate power systems with maximum generation capacity close to the collapse point, leading to high risks of failure and blackouts [5]. All economic and social activities related to energy optimization, including renewable energy and geological storage, are essential for 
energy systems' planners and utility operators. Therefore, for a long period, the attention of decision-makers has been attracted by sustainable energy decision-making using multi-criteria decision analysis, which provides a method to eliminate [6]. Therefore, sustainable operation recommends a broader perspective, balancing technical, technological, economic, environmental, institutional, social appraisals for optimum benefits for long-run sustainability [7]. Power systems reliability and stability of supply, security, flexibility, and proper operation owing optimum deployment of smart technologies and storage systems that make the possible increase in profitability, satisfaction in services delivery, and competitiveness in the market [8-10]. Managing supply and demand sides and propose a quick response to transient increases or decreases in power supply from alternating renewable sources, the different storage solutions may be hierarchies based on their ability, ensuring dynamic pricing structures are recommended [11].

The concept of energy sustainability is reported as "Meeting energy needs of the present generation without compromising future generations in terms of meeting their energy demands." Climate change and global warming are overwhelmingly influenced by human activities, global industrialization, and lifestyle changes. That results in increasingly global energy demands relying on fossil fuel utilization and enormous organic and non-organic waste generation. The recent global trends in society's modernization and lifestyle change alter a dramatic increase in municipal solid waste generation that remains a continuing matter of interest within multi-disciplinaries. Energy sector sustainability requires an intensive study of multidimensional factors that barely affect climate change and global warming [12]. Climate change causes analysis and eliminating influential factors are considered as pressing global efforts to save the world and prosper socio-economic. In this instance, root cause analysis can eradicate pernicious factors of climate change through introducing reasonable alternatives to conquer an intricate global challenge. The main trinary factors (energy, climate, economic) have inter-related impacts. For example, the climate change impacts can disrupt energy supply causing power outages, and alter public services that can amount to substantial economic losses. Therefore, the proposed energy strategy must be more resilient and adaptable to the affective components to deal with these challenges. Also, climate change affects the energy sector in various ways, such as extreme weather events (storms, floods, landslides, and fire), seasonal changes (water resources availability and unusual temperature variation, rising sea levels, and permafrost thaw (surface subsiding that can damage to pipelines).

The role of renewable in the heat and the transport sector has been given a lot of importance. Still, in the real sense, electricity is the energy sector that contributes more to reducing utilization of fossil fuels in the energy mix. Innovation in the energy sector has increased the supply cost of energy and reduced the costs of energy. In addition, the innovations have made it possible to integrate various energy sectors, thus increasing fossil fuel systems efficiency. It has also enabled the increase in the share of renewable energy in the overall energy mix [13]. Therefore, low carbon technologies and energy efficiency are playing an essential role in the national energy strategies. Moreover, reducing environmental pollution and conservation of virgin resources is potentially allowed by recycling waste. When waste management links with psychological well-being, it becomes at the center of attention that encourages the spread of importance by public awareness programs [14].

\section{Environment sustainability}

Climate change phenomenon is highly influenced by human activities like fossil fuel consumption as an option of energy production. However, nonrenewable resource deployment can also be considered environmental-friendly and cost-effective in biomass and waste to energy [15]. According to reports, the air quality in low and middle-income countries is alarmed that $97 \%$ of cities with over 100,000 inhabitants do not meet the World Health Organization (WHO) air quality guidelines [16].

Before the twentieth century, environmental sustainability was not addressed as a global challenge. As a result, the ISO 14,001 standard was promulgated in 1996, in compliance with the British BS 7750 standard in terms of Environmental Management System (EMS) [17]. However, the adaption of the ISO 14,001 within the global economic zones countries remains challenging [7]. Recently, increased concerns associated with the environmental impact of anthropogenic activities, compounded by energy security concerns and economics, have been due to continuous population growth and rising living standards.

Some fossil fuel substitutes may include biomass and waste-derived fuels, which are solid fuels and are important for mitigating greenhouse gases. Locally, combining compost of organic waste and recycling organic waste is found to be the most sustainable waste management system. Also, biodiesel production is one crucial strategic issue in the renewable energy context.

\section{Water sustainability}

Energy and water supply have been integrated demands in the context of daily life. Which has found that water and energy are highly affected quantitively and qualitatively by the increased rate of urbanization. As an obvious solution, addressing future water problems by wastewater treatment and reuse to preserve water resources. Combined energy production (electricity and heat) utilizing wastewater plans can contribute to this concept. Wastewater plants' main aim is to control water pollution and generate energy using digester gas ignition with high generation potentials of heat energy [18]. To collect, manage and recycle solid waste is an important problem area for many industries. Research shows that recycling and compost solid waste will reduce the emission of 
greenhouse gases, thus reducing carbon dioxide and carbon equivalent, and will alternatively promote energy savings. However, waste transportation and collection have been found to emit greenhouse gas, thus to control this, solid waste composting should be combined with some reduction in the collection days of the organic waste.

Water pollution contains dreadful reports due to water contamination that treats directly human beings in terms of child deaths (525,000 annually under the age of five) due to trivial diseases like diarrhea, water scarcity (near 40 of the world population is faced); over $90 \%$ of the epidemics, diseases and inevitable natural accidents are due to clean water inaccessibility [19].

Economic growth and human prosperity are underpinned by water and energy, closely interlinked and interdependent valuable resources. Thermally driven and membrane separation processes are the two commercial desalination technologies. Innovative membrane materials are proposed for future sustainability, but they need some time to bring back profits [20].

\section{Environmental sustainability and indicators}

Sustainability indicators, including quantitative indicators application in energy systems, measure sustainability reliably for renewable energy sources [2]. These indices (indicators) aim to explore scalable information on a broader scheme to contribute to decision-making. Sustainability scale is the set of the ruling of sustainability degree. The more the scales of indicator, the greater the exactitude.

To analyze the interactions between the environment and human activities systematically, ecology and environment indicators are used. These indicators or indices are applied to optimize the total systems lifecycle, productivity, and material cycle from being raw materials to a finished product in the way of sustainability to ultimately dispose of generated wastes [21]. Usually, ecological indicators have been used to minimize environmental impacts and increase efficient utilization of energy, capital, and resources optimally. This is done by integrating production and consumption of resources (energy, natural, raw materials, etc.) in the aspect of sustainable modeling design, production, supply, and consumption. The decision-making process based on indicators analysis required a comprehensive evaluation. For example, to develop or reform energy sector policies and strategies, these sequence of steps are suggested [22]:

- fortify the policy of energy reduction mechanism rather than traditionally focuses on the supply side and energy import.

- develop energy efficiency law and regulation, and building energy performance regulation.

- timeline appoint skilled workforce for energy-efficient building application and accreditation of public, commercial, and industrial facilities.
- $\quad$ issue the building standard energy performance certificate.

- define frankly feasible targets to be achieved (greenhouse gasses reduction, boom out energy-efficient appliances, loss reduction, refurbishment of existing buildings, etc.) based on specific timelines.

The aim of environmental sustainability is to ensure that human welfare has been improved. There are four environmental sustainability specific criteria [15]; the first one is regeneration, efficient use of renewable resources as there use is not exceeding the long-term rates of natural regeneration. The second criterion is substitutability; nonrenewable resources are used efficiently. The third criterion is assimilation, limiting the release of pollutants to the environment concerning their waste assimilative capacity. Then the last one is to avoid irreversibility. The above criteria are used to contemplate five inter-related objectives to advance environmental policies in a sustainable development context. The objectives include maintaining ecosystem integrity through managing natural resources efficiently, decoupling environmental pressures from economic growth, enhancing the quality of life, improving global environmental interdependence through improving governance and cooperation, and measuring progress using environmental indicators and indices. The five inter-related objectives to advance environmental policies in the context of sustainable development are as follows:

- Maintaining ecosystem integrity through managing natural resources efficiently.

- Decoupling environmental pressures from economic growth

- Enhancing life and welfare quality.

- Improving global environmental interdependence through improving governance and cooperation.

Measuring progress using environmental indicators and indices. The most important environmental problems are acid rain, ozone depletion and global warming. Global warming has been found to cause climate change, which mostly causes increase of temperature, cutting emissions, technological innovations, and bracing for change. These are the three challenges that global warming possesses for the policy. Ozone layer helps in balancing the earth's energy and also absorbs the biological harmful solar ultraviolet radiation. Acid rain occurs when sulfur dioxide and nitrogen oxides react in the atmosphere with water, oxygen and other chemicals, thus forming some acidic compounds. The rate of the reactions is accelerated by sunlight. Acid rains damage plant leaves and it reduces soil nutrition level. Using other alternatives as energy sources other than the fossil fuel energy can contribute to solving the acid rains problems. The transport sector has a great environmental impact because all its energy is from fossil fuels, causing global warming through air pollution from both direct and indirect emissions. To solve this issue, the 
transport patterns are being changed to cycling, walking and either using the public transport sector more systematically. To address this problem in a way that will be beneficial to evaluate the relations between exergy and environmental problems [21].

For the country level to provide transparent and objective ways of measuring and demonstrating energy and environmental sustainability using indices and indicators are advisable. Assessment of environmental-friendly sustainable energy has features like a subject focus on human activity and nature-related, a direction towards the longterm, and the concept of justice between current humans and future generations [23].

The environmental indices have to be put in place in a successful way the following some essential factors. For instance, the impact of energy demand increase and economic activities on the environment like pollutions; the effects of resource productivity on the economy; the effects of environmental dilapidation on economic productivity; and the effects of environmental improvement on society like improved human well-being.

According to [23], there are four environmental indices which include, environmental vulnerability index. These indices assess the exposure of the physical environment with the use of fifty environmental indicators. The second one is environmental performance index, which tries to quantify the countries' environmental performance in relation to each other using twenty-five indicators. The third environmental index is an ecological footprint which is calculated by the global track network and measures. It deals with the total amount of goods and services consumed by a country's inhabitants per capita. The last environmental index is happy planet index which represents a ratio of human well-being to environmental impact. It assesses the efficiency of ecology to deliver a certain level of biased human well-being. Some of the environmental indices and their functions are as follows:

- Environmental vulnerability index: To evaluate the physical environment

- Environmental performance index: To qualify environmental performance

- Ecological footprint index: To track the global environmental status

Happy planet index: To show human well-being ratio to environmental impact. Under the environmental indicators, the most important goal that researchers consider is reducing pollutant emissions by any means in any form, such as greenhouse gas emissions, waste recycling and reuse, lifestyle and socio-physiology values, ecosystem stability, etc. The indicators which have been used to study energy sustainability demonstrated with many criteria that have been verified based on various questions and scenarios example [24]:

- Is the indicator not redundant?

- Is it linked to the concept of sustainability? I
- Is it comparable?

- Is it characterized by the pressure of values for all countries?

- Is it analyzed by current scientific literature?

By applying the criteria as mentioned above, there are nine indicators: atmosphere and air pollutants of the greenhouse emissions, the available amount the government spends on environmental protection, the total recycled and reused waste from electrical and electronic equipment, the total recycled and reused waste from vehicles, the total recycled materials the solid waste collected within, the share of renewable energy in electricity, in transport, heating and cooling, and lastly the percentage change of primary energy consumption in a specific period.

Policymakers and the general public would appreciate it if they know the environmental situation at any given moment, and a single indicator would be ideal [25]. Some of the common environmental sustainability indicators are reported as follows [26-29]:

1- Gross Domestic Product (GDP) gives the total value of goods and services produced in a specific time frame, usually a year. It is a popular indicator in the economic sphere but does not apply in the social sphere.

2- Human Development Index (HDI) measures the average achievement in the three primary aspects of human development; knowledge, longevity, and improved living standards. Life expectancy defines longevity, enrollment in schools, and adult literacy provides awareness, and the GDP per capita defines the living standard. The UN development program published it.

3- Both GDP and HDI must satisfy salience, credibility, and legitimacy. Salience means that the indicators are useful, applicable, and attractive to the user. Credibility means that the pointers are valid and make scientific sense. Finally, legitimacy touches pointers' perception from the perspectives of users, stakeholders, businesses, trade unions, and environmental non-governmental organizations.

4- Environmental Sustainability Index (ESI) measures overall progress towards environmental sustainability for 142 countries measured by the World Economic Forum. It provides a more analytical approach to environmental decision-making and allows comparison of the progress among the nations.

5- Dashboard of Sustainability (DS) is software developed by the European Union's Joint Research Centre at Ispra and represents the complicated relationship between environmental, economic, and social issues. Moreover, it provides information in a way palatable to decision-makers and the general public.

6- Well-being Index (WI) is called stress index, combines two types of indicators then combines them. The first type has thirty-six pointers for health, population, 
wealth, freedom, peace, crime, equity, communication, and education. The other type has fifty-one land, water, air, and energy.

7- Ecological Footprint (EF) is the area of productive land needed to maintain its current consumption ratio while using the prevailing technology to absorb wastes and calculated for a specific population.

8- Living Planet Index (LPI) assesses the overall global state of the ecosystem using national and international data on the impact of human activities on the environment.

9- Direct Material Consumption (DMC) measures the total sum of the domestic extraction flows, includes imported but excludes exported.

European countries have set goals on climate and energy indexes, and they have established challenging levels to achieve a more safe, competitive, and sustainable energy system. Energy efficiency, renewable energy sources, and some of the goals that suit to be useful and strategic and can help reach the European energy goals [24]. According to the studies, reduction of fossil fuel emissions, low energy costs, security in the supply of energy, and industrial developments are some of the factors which have led to the growth of the European countries and the creation of employment to residents and non-residents. Europeans will be able to rely on resources imports. They will be able to boost their security of supply of some critical resources used in the new technologies when they embrace high recycling rates. Recycling energy sources has brought about a somehow complete solution to the most sought sustainable energy solution. When a country has a sustainable energy system, its local communities are transformed, and the development becomes a shared factor of strength. Economic growth and fossil fuel emissions require decoupling to improve end-use energy efficiency.

\section{Exergy as the tool for environmental sustainabil- ity}

Exergy is the result of the interactions of substances under consideration and the common reference substances in the natural environment [21]. It can increase the utilization of green energy and technologies in the context of resources and energy efficiency. Referring to the connection between the second law of thermodynamics and environmental impact, environmental effects are reduced due to low energy losses when energy efficiency is increased. Eco-exergy is used to estimate how sustainable or healthy an ecological system is. It can be used as an indicator from a sustainable point of view to evaluate agricultural production. Eco-exergy facilitates policymakers and strategy developers to come up with viable environmentally friendly energy systems planning. To emphasize the importance of environmental impacts, economic yield in natural resources saving and economic investment boosting.
Exergy is known as one of the most effective tools in providing the finest environmental conditions. This is achieved by consuming nonrenewable natural (fossil) resources, thus increasing energy security and directly reducing environmental and socio-economic distresses. Exergy is a central concept in attaining sustainable development because exergy-based indicators can indicate the environmental effects associated with resource utilization and depletion, climate change mitigation, and greenhouse gas emissions reduction. To obtain sustainable development goals (SDGs) related to energy and environmental endeavors, exergy losses evaluation meeting the lower level of acceptance is important. Furthermore, exergy analysis makes communication possible between professionals and stakeholders for better decision-making. Understanding how exergy and environment, ecology, and sustainable development intertwine and the interlink requirement and impact evaluation as the whole system is important.

\section{Shaping environmental sustainability by help of energy strategy and policy}

Energy strategy and policy are of profound concern not only for territory, but this concern affects the region and globally. Based on the policy cycle, setting objectives, program costing, implementation and monitoring measures are well-known variables considered by energy policymakers. But often, the political segment is ignored by an oversight. While, based on the literature finding, shaping energy politics plays a critical role in the reality of energy policy framing for long-run sustainability. Over past decades, energy policies have been framing with diverse of politics for the specific aims. Sometimes, policy formulated as a course of action for a distinct territory without treating the global interest, but this matter has had its exceptions. Based on the academic research methods and techniques, at first data literature review is conducted. Then an inclusive analysis curried out, associated with global energy policies and politics' significances, shortcomings, drawbacks, barriers, and concluded with recommendations. This section aims to evaluate the energy policies within political constraints around the globe. Then the research efforts offer a conceptual framework for framing an energy policy within political transitions considering the sustainability dimensions along with energy accessibility, affordability, disparity, safety, security, use efficiency, supply and production efficiency, cost-effectiveness, and environmental impacts factors [30]. At last, this study underscores the need for consensus of all the associated factors, including the missing factors/research gaps over-arching point for a coherent energy policy with distinguishing of immediate political situations of a territory.

When we talk about energy sustainability, instantly, energy balance and sustainability dimensions such as economic, environmental, social, technical, and institutional 
become a matter of focus. In which to meet the present energy needs without a decline of the future demand [31]. Among these dimensions, herein energy policy and politics under institutional sustainability is a subject at hand. All the policy cycles must be implied in order to be inclusive and accountable against policy benchmarks. Preparing a policy and for energy sector needs a multidimensional analysis and investigations. Make it mysterious when the policymakers miss the significant points. Based on the policy cycle, setting objectives, program costing, implementation, and monitoring measures are wellknown variables often considered by energy policymakers [32]. But, an oversight ignores the political segment.

There is a rapidly growing literature on energy policy and politics under energy sustainability, which are conducted partially. Literature asserts that social scientists for a long time have worked to understand the many aspects of energy, in which they rely on economic costs and benefits, social implications, and environmental repercussion, to name just a few common topics. The recent finding of Energy Research and Social Science indicates the increasing emphasis on energy security, or energy and security; still, it remains a research or policy gap. Sovacool has targeted the politicians and censured that they are quick to talk about energy security, but loathe to define it [33]. Cohen et al. l. [34] has noted that somehow the politicians' discourse around energy more often treats energy interdependence as problematic. Therefore, in view of the seriousness of the subject, shaping energy politics plays a critical role in the reality of energy sustainability. The consensus view seems that energy policy also matters because it is sensitive to many interacting factors.

Therefore, this study outlines the need for consensus of all the associated factors, including the missing factors/research gaps over-arching point for a coherent energy policy. That necessitates a sustainable dialogue between and among scholars and policymakers on the energy matter.

Policy is a principle or a course of action, which it applies to maintain or change the status of targeted scopes. Energy policy as a tool for enhancing the persistence of energy resources' appropriate exploitation and deployment is known as essential [35]. Conversely, an immature energy policy can lead a nation to an irrecoverable consequence. Over past decades, energy policies have been framing with diverse politics for specific aims. Sometimes, policy formulated as a course of action for a distinct territory without treating the global interest, but this matter has had its exceptions. For instance, President Jimmy Carter (1977-1981) reconsiders the energy politics and proposed six programs for legislative action, while, the oil producing and consuming countries were affected by these programs. These five programs were preventive and corrective actions; 1) 16\% energy conservation per day, 2) transition to domestic energy resources, 3) doubling of coal production and fast development of nuclear capacity, 4) curtailment of oil import, 5) regulation for natural gas and 6) creation of Department of Energy. As observed, the lack of equilibrium between theoretical and empirical measures for energy policy development is known as a bottleneck. This is due to the lack of well-wisdom of these parameters from politics point of view.

\section{Conclusion}

This study first conducts a short literature review to sort and outline research findings, shortcomings, parameters, and variables in energy and sustainable environmental development. At first glance, the main points are highlighted through a structured approach and techniques. Then an assessment of barriers characteristics and identification of variables are the primary steps toward research modeling. Finally, the scenarios, challenges, possible solutions and future outlook are discussed. This study examined different areas related to the environment and energy sustainability: disseminating renewable and electrical network stability; encouraging renewable resources; demonstrating storage systems as the leading player of electric power systems security and reliability; the energy market; as well as analyzing policies and strategies as the primary motive for environmentally-friendly energy production. Energy savings, efficiency, and conservation and their tools and techniques are pointed out in brief [11].

This review indicates that to reduce the use of fossil fuel and to increase in any chance the use of renewable energy sources required a multidimensions analysis to improve sustainability of the energy sectors. This is because there will be reduced air pollution, thus reducing the global warming effects, which most bring about a negative climate change affecting the energy sector negatively.

\section{References}

[1] Danish MSS, Senjyu T, Ibrahimi AM, Ahmadi M, Howlader AM (2019) "A managed framework for energy-efficient building" Journal of Building Engineering (vol. 21, pp. 120128) https://doi.org/10.1016/j.jobe.2018.10.013

[2] Liu G (2014) "Development of a general sustainability indicator for renewable energy systems: A review" Renewable and Sustainable Energy Reviews (vol. 31, pp. 611-621) https://doi.org/10.1016/j.rser.2013.12.038

[3] Basiago AD (1998) "Economic, social, and environmental sustainability in development theory and urban planning practice" The Environmentalist (vol. 19, no. 2, pp. 145-161) https://doi.org/10.1023/A:1006697118620

[4] Danish MSS, Senjyu T, Danish SMS, Sabory NR, K N, et al. (2019) "A Recap of Voltage Stability Indices in the Past Three Decades" Energies (vol. 12, no. 8, pp. 1544) https://doi.org/10.3390/en12081544

[5] Danish MSS, Yona A, Senjyu T (2015) "A Review of Voltage Stability Assessment Techniques with an Improved Voltage Stability Indicator" International Journal of Emerging Electric Power Systems (vol. 16, no. 2, pp. 107-115) https://doi.org/10.1515/ijeeps-2014-0167

[6] Wang J-J, Jing Y-Y, Zhang C-F, Zhao J-H (2009) "Review on multi-criteria decision analysis aid in sustainable energy decision-making" Renewable and Sustainable Energy 
Reviews (vol. 13, no. 9, pp. 2263-2278) https://doi.org/10.1016/j.rser.2009.06.021

[7] Danish MSS, Senjyu T, Zaheb H, Sabory NR, Ibrahimi AM, et al. (2019) "A novel transdisciplinary paradigm for municipal solid waste to energy" Journal of Cleaner Production (vol. 233, pp. 880-892)

[8] Yaqobi MA, Matayoshi H, Danish MSS, Urasaki N, Howlader $\mathrm{AM}$, et al. (2018) "Control and energy management strategy of standalone DC microgrid cluster using PV and battery storage for rural application" International Journal of Power and Energy Research (vol. 2, no. 4, pp. 53-68) https://doi.org/10.22606/ijper.2018.24001

[9] Ibrahimi AM, Howlader HOR, Danish MSS, Shigenobu R, Sediqi MM, et al. (n.d.) "Optimal Unit Commitment with Concentrated Solar Power and Thermal Energy Storage in Afghanistan Electrical System" International Journal of Emerging Electric Power Systems

[10] Danish SMS, Ahmadi M, Danish MSS, Mandal P, Yona A, et al. (2020) "A coherent strategy for peak load shaving using energy storage systems" Journal of Energy Storage (vol. 32, pp. 101823) https://doi.org/10.1016/j.est.2020.101823

[11] Piacentino A, Duic N, Markovska N, Mathiesen BV, Guzović $\mathrm{Z}$, et al. (2019) "Sustainable and cost-efficient energy supply and utilisation through innovative concepts and technologies at regional, urban and single-user scales" Energy (vol. 182, pp. 254-268) https://doi.org/10.1016/j.energy.2019.06.015

[12] Danish MSS, Sabory NR, Wali M, Lotfy ME, Senjyu T (2019) "A sustainable building planning, modeling, and optimization within the smart city appraisal" International Journal on: Proceedings of Science and Technolgy Sepang, Malaysia, IEREK - pp. (in press).

[13] Guelpa E, Bischi A, Verda V, Chertkov M, Lund H (2019) "Towards future infrastructures for sustainable multi-energy systems: A review" Energy (vol. 184, pp. 2-21) https://doi.org/10.1016/j.energy.2019.05.057

[14] Hafizyar M, Arsallan AR, Sabory NR, Danish MSS, Senjyu T (2021) "Smart and sustainable township: An overview" In: Danish MSS, Senjyu T, Sabory NR - editors. Sustainability Outreach in Developing Countries Singapore, Springer Singapore - pp. 65-80. https://doi.org/10.1007/978-981-157179-4_5 (http://link.springer.com/10.1007/978-981-157179-4_5) Accessed: 18 November 2020

[15] Urbaniec K, Mikulčić H, Rosen MA, Duić N (2017) “A holistic approach to sustainable development of energy, water and environment systems" Journal of Cleaner Production (vol. 155 , pp. 1-11) https://doi.org/10.1016/j.jclepro.2017.01.119

[16] Danish MSS, Zaheb H, Sabory NR, Karimy H, Faiq AB, et al. (2019) "The Road Ahead for Municipal Solid Waste Management in the 21st Century: A Novel-standardized Simulated Paradigm" IOP Conference Series: Earth and Environmental Science IOP Publishing, vol. 291 - pp. 1-5. https://doi.org/10.1088/1755-1315/291/1/012009

[17] Heras-Saizarbitoria I, Boiral O, Allur E (2018) "Three Decades of Dissemination of ISO 9001 and Two of ISO 14001: Looking Back and Ahead" In: Heras-Saizarbitoria I - editor. ISO 9001, ISO 14001, and New Management Standards Cham, Springer International Publishing - pp. 1-15. https://doi.org/10.1007/978-3-319-65675-5_1

(https://doi.org/10.1007/978-3-319-65675-5_1)

Accessed: 17 July 2021

[18] Danish MSS, Senjyu T, Sabory NR: editors (2021) "Sustainability Outreach in Developing Countries," 1st ed. Singapore, Singapore, Springer Singapore. 202 p. ISBN: $\mathbf{9 7 8 9 8 1 1 5 7 1 7 8 7}$

(https://www.springer.com/gp/book/9789811571787) Accessed: 16 July 2020

[19] Awasthi MD, Pandey MK, Chauhan T, Danish MSS, Kumar D, et al. (2021) "Contemporary developments in waste water treatment technologies" Eco-Friendly Energy Processes and Technologies for Achieving Sustainable Development: Pennsylvania, United States, IGI Global - pp. 196-219. https://doi.org/10.4018/978-1-7998-4915-5 (http://services.igi-global.com/resolvedoi/re-

solve.aspx?doi=10.4018/978-1-7998-4915-5) Accessed: 18 November 2020

[20] Shahzad MW, Burhan M, Ang L, Ng KC (2017) “Energy-water-environment nexus underpinning future desalination sustainability" Desalination (vol. 413, pp. 52-64) https://doi.org/10.1016/j.desal.2017.03.009

[21] Bilgen S, Sarıkaya İ (2015) "Exergy for environment, ecology and sustainable development" Renewable and Sustainable Energy Reviews (vol. 51, pp. 1115-1131) https://doi.org/10.1016/j.rser.2015.07.015

[22] Elsland R, Divrak C, Fleiter T, Wietschel M (2014) “Turkey's Strategic Energy Efficiency Plan - An ex ante impact assessment of the residential sector" Energy Policy (vol. 70, pp. 14-29) https://doi.org/10.1016/j.enpol.2014.03.010

[23] Olafsson S, Cook D, Davidsdottir B, Johannsdottir L (2014) "Measuring countries' environmental sustainability performance - A review and case study of Iceland" Renewable and Sustainable Energy Reviews (vol. 39, pp. 934-948) https://doi.org/10.1016/j.rser.2014.07.101

[24] Cucchiella F, D’Adamo I, Gastaldi M, Koh SL, Rosa P (2017) "A comparison of environmental and energetic performance of European countries: A sustainability index" Renewable and Sustainable Energy Reviews (vol. 78, pp. 401413) https://doi.org/10.1016/j.rser.2017.04.077

[25] Statistics, knowledge and policy: Key indicators to inform decision making (2005) Text Paris, France, Organization for Economic Co-operation and Development (OECD). (https://www.oecd-ilibrary.org/economics/statisticsknowledge-and-policy_9789264009011-en) Accessed: 18 July 2021

[26] De Bhowmick G, Sarmah AK, Sen R (2019) "Zero-waste algal biorefinery for bioenergy and biochar: A green leap towards achieving energy and environmental sustainability" Science of The Total Environment (vol. 650, pp. 2467-2482) https://doi.org/10.1016/j.scitotenv.2018.10.002

[27] Kaygusuz K (2009) "Energy and environmental issues relating to greenhouse gas emissions for sustainable development in Turkey" Renewable and Sustainable Energy Reviews (vol. 13, no. 1, pp. 253-270) https://doi.org/10.1016/j.rser.2007.07.009

[28] Özokcu S, Özdemir Ö (2017) "Economic growth, energy, and environmental Kuznets curve" Renewable and 
Sustainable Energy Reviews (vol. 72, pp. 639-647) https://doi.org/10.1016/j.rser.2017.01.059

[29] Ferretti P, Zolin MB, Ferraro G (2020) "Relationships among sustainability dimensions: evidence from an Alpine area case study using Dominance-based Rough Set Approach" Land Use Policy (vol. 92, pp. 104457) https://doi.org/10.1016/j.landusepol.2019.104457

[30] Danish MSS, Senjyu T, Sabory NR, Danish SMS, Ludin GA, et al. (2017) "Afghanistan's aspirations for energy independence: Water resources and hydropower energy" Renewable Energy (vol. 113, pp. 1276-1287) https://doi.org/10.1016/j.renene.2017.06.090

[31] Danish MSS, Sabory NR, Ershad AM, Danish SMS, Yona A, et al. (2016) "Sustainable Architecture and Urban Planning trough Exploitation of Renewable Energy" International Journal of Sustainable and Green Energy (vol. 6, no. 3, pp. 1) https://doi.org/10.11648/j.ijrse.s.2017060301.11

[32] Nance MT, Boettcher WA (2017) “Conflict, cooperation, and change in the politics of energy interdependence: An introduction" Energy Research \& Social Science (vol. 24, pp. 1-5) https://doi.org/10.1016/j.erss.2016.12.020

[33] Sovacool BK (2010) "The routledge handbook of energy security," 1st ed. New York, USA, Routledge. 455 p. ISBN: 9781-136-85063-9

[34] Suck A (2005) "The politics for a sustainable energy industry: Renewable energy policy in the United Kingdom and in Germany," 1st ed. Cheltenham, United Kingdom, Edward Elgar Publishing. p. ISBN: 978-1-84542-800-6 (https://www.elgaronline.com/view/9781845423872.00016.xml) Accessed: 18 July 2021

[35] Danish MSS, Sabory NR, Danish SMS, Ludin GA, Yona A, et al. (2016) "An Open-door Immature Policy for Rural Electrification: A Case Study of Afghanistan" International Journal of Sustainable and Green Energy (vol. 6, no. 3, pp. 8-13) https://doi.org/10.11648/j.ijrse.s.2017060301.12 